14.3

\title{
Разработка термометрической перчатки для мониторинга конечностей человека, получившего хладотравму*
}

\author{
(C) К.Н. Большев, В.А. Иванов, А.А. Степанов, А.С. Андреев \\ Институт физико-технических проблем Севера им. В.П. Ларионова СО РАН, \\ 677980 Якутск, Россия \\ e-mail: asandreev92@mail.ru
}

(Поступило в Редакцию 2 декабря 2017 г.)

Описан прибор для автоматизированного мониторинга температуры конечностей человека. Данный прибор, названный „термометрическая перчатка“, разработан авторами для применения в целях лечения хладотравм. Термометрическая перчатка осуществляет опрос температуры поверхности конечности в нескольких точках установки, производит автоматическую регистрацию и запись значений температуры во внутреннюю память. Приведены два варианта прототипов прибора и результаты апробации и опытной эксплуатации прототипов.

DOI: 10.21883/JTF.2018.10.46488.2584

В суровых климатических условиях Республики Саха (Якутия), когда температура зимой достигает $-60^{\circ} \mathrm{C}$, проблемы, связанные с обморожениями и переохлаждениями людей, имеют неоспоримую актуальность. Подавляющее число хладотравм составляют обморожения конечностей.

В год в ожоговое отделение г. Якутска поступают около 200 пострадавших с хладотравмами, из них сразу с улицы в больницу привозят около 5-7 человек. В остальных случаях человека сначала заносят домой, тормошат, растирают руки, повреждая сосуды, и только потом обращаются к врачам.

При серьезном обморожении конечностей для максимально возможного восстановления тканей необходимо соблюдать условие медленного и постепенного отогревания отмороженных тканей за счет естественного теплообмена кровообращением. Для этого травмированную конечность максимально теплоизолируют и применяют различные средства для ускорения кровообращения. При этом важное значение имеет постоянный контроль температуры объекта, а именно крайних точек конечности - пальцев. Такой контроль подразумевает использование надежного и точного измерительного оборудования. Также измерение температуры травмированных тканей важно для постановки точного диагноза и определения степени обморожения, в зависимости от которого выбирается способ оказания первой медицинской и врачебной помощи, который является решающим в лечении и определяющим исход лечения [1].

Привлекательной стороной этого метода обследования больных является его абсолютная безвредность, возможность многократных, повторных, динамических исследований и относительная простота в интерпретации полученных результатов [2,3]. В частности, детальное изучение температурных изменений в тканях охла-

\footnotetext{
* Вторая российская конференция с международным участием „Физика - наукам о жизни“ (Санкт-Петербург, 18-22 сентября 2017 г.)
}

жденного сегмента дает возможность диагностировать наличия оледенений тканей. Для того чтобы доказать наличие оледенения тканей, необходимо подтвердить минусовые температуры в тканях. Температурный контроль позволяет диагностировать не только обморожения, но и такие заболевания, как сахарный диабет, мастопатия, аденома.

Целью нашей разработки является непрерывная периодическая регистрация температуры кончиков пальцев человека в течение определенного промежутка времени, которая позволит медикам оценить эффективность тех или иных методик, применяемых при лечении подобных травм. Так как больной при этом должен иметь возможность передвигаться, то прибор должен быть автономен и компактен. На основе полученного АО НПП „Эталон“ опыта при разработке систем температурного мониторинга грунтов, по техническому заданию Института физико-технических проблем Севера им. В.П. Ларионова было принято решение по внедрение данных технических заделов при разработке „термометрической перчатки“. Данные технические решения

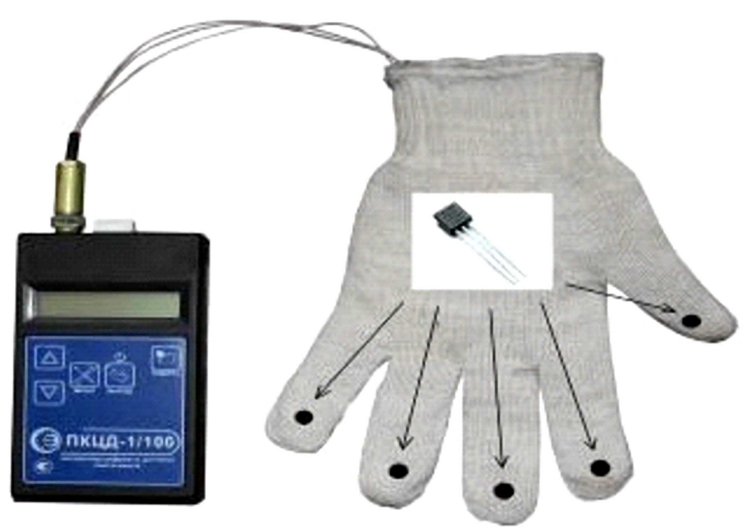

Рис. 1. Макет термометрической перчатки. 


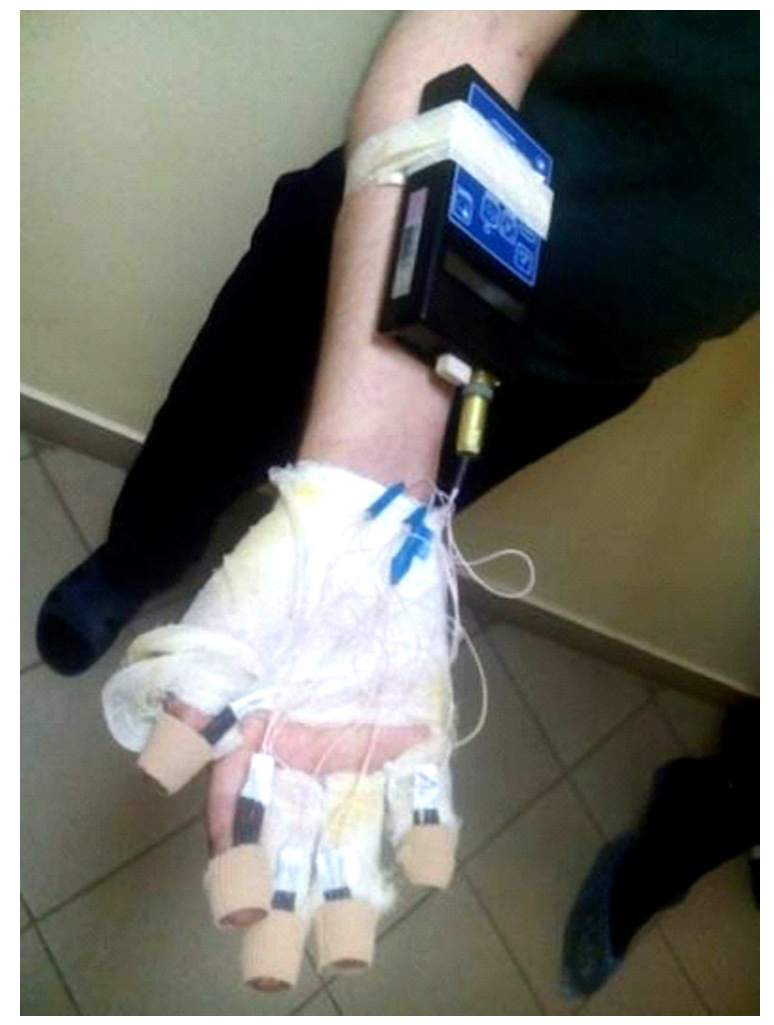

Pис. 2. Установка датчика на пациенте.

позволили повысить точность и надежность измерений, упростить конструкцию разрабатываемого изделия.

Был изготовлен прототип термометрической перчатки (рис. 1) со следующими основными характеристиками:

- диапазон измерений от -55 до $+125^{\circ} \mathrm{C}$;

- точность измерений $0.5^{\circ} \mathrm{C}$. Каждый температурный датчик DS18B20 имеет уникальный 64-битный последовательный код, который позволяет общаться со множеством датчиков DS18B20, установленных на одной шине. Такой принцип позволяет использовать один микропроцессор, чтобы контролировать множество датчиков DS18B20, распределенных по большому участку;

- программируемое разрешение от 9 до 12 bit, которое может сохраняться в EЕPROM-памяти прибора;

- в дополнение датчик DS18B20 может питаться напряжением линии данных („parasite power“) при отсутствии внешнего источника напряжения.

В качестве логгера, записывающего показания чувствительных элементов, нами используется портативный контроллер цифровых датчиков ПКЦД-1/100 (далее контроллер) предназначен для считывания результатов измерения с цифровых датчиков температуры. По функциям, назначению и области применения прибор аналогичен ПКЦД-1/16, но имеет ряд преимуществ и усовершенствований. Встроенные алгоритмы измерения емкости линии связи позволяют устойчиво считывать измерения с датчиков на расстоянии 100 и более метров, при емкости линии до 15000 pF. Контроллер поддерживает до 100 датчиков в сети, с интервалом опроса от $10 \mathrm{~s}$ до $1 \mathrm{~h}$. Связь с ПК осушествляется через порт USB, при подключении к USB контроллер может работать без элемента питания. Емкость энергонезависимой памяти - $64 \mathrm{kB}$. ПКЦД-1/100 может работать в режиме логгера, т.е. автоматически сохранять данные в энергонезависимой памяти с заданной периодичностью, ресурс автономной работы в режиме логгера составляет около 20 суток (изменяется в зависимости от емкости аккумулятора и окружающей температуры).

Датчики устанавливались на кончиках пальцев правой руки человека (рис. 2), затем на пальцах левой руки. Период опроса датчиков был установлен на $60 \mathrm{~s}$. (Дата испытания - 2 декабря 2015 г. с 11:00 до 14:00.) С применением разработанного прототипа была выполнена опытная эксплуатация, в ходе которой получены

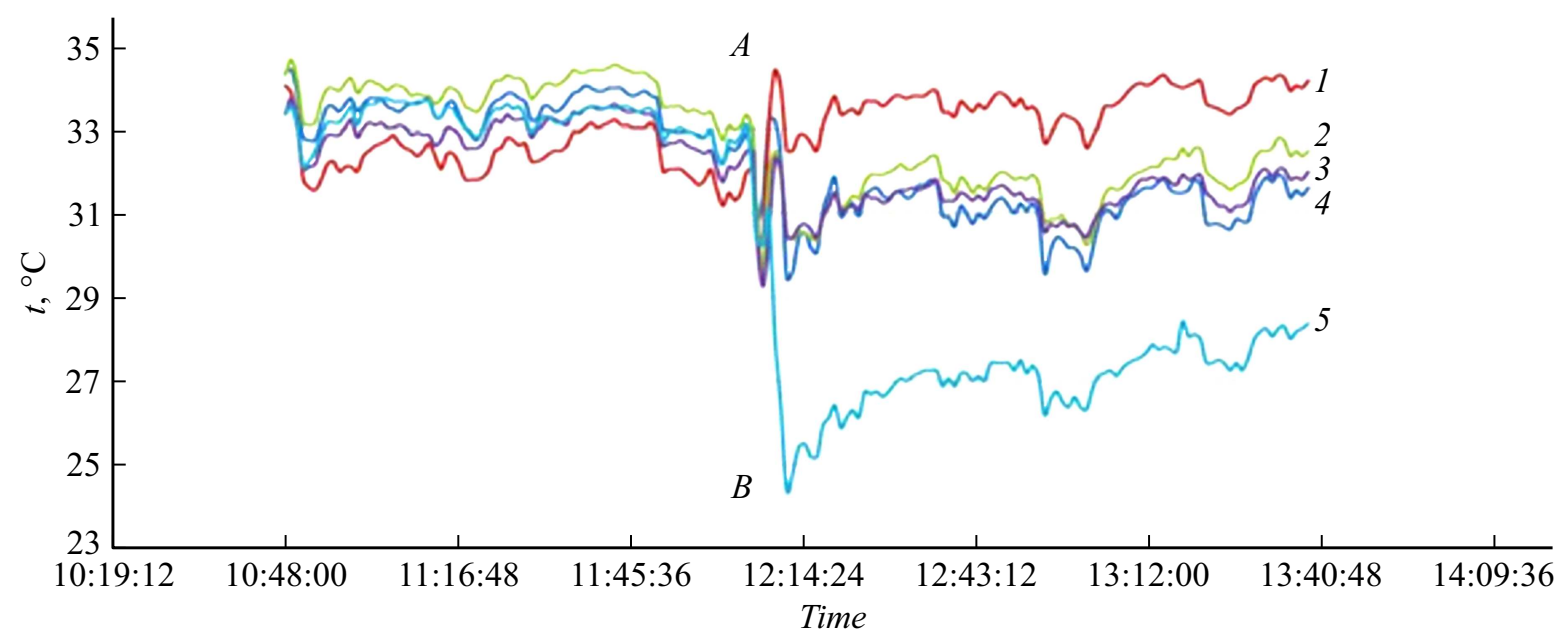

Рис. 3. Результаты эксплуатации. $A-$ момент смены цифровых датчиков температуры с правой на левую руку. $B-$ датчик прикреплен к основанию мизинца левой руки, получившей тяжелую степень обморожения. Температура: 1 - большого пальца, 2 - указательного, 3 - среднего, 4 - безымянного, 5 - мизинца. 


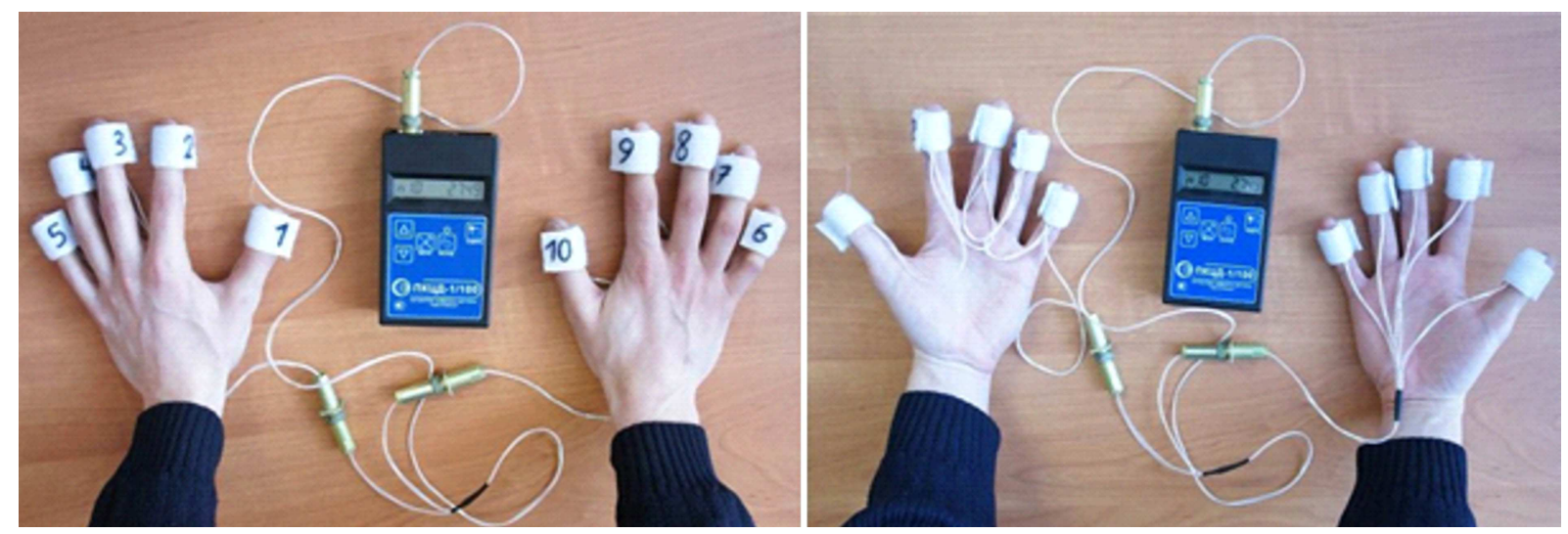

Рис. 4. Общий вид системы.

первые результаты (рис. 3). В качестве объекта выступал пациент ожоговой терапии Республиканской больницы № 2 с обморожением конечностей, уже получивший первую помощь.

По итогам опытной эксплуатации было принято решение по разработке термометрической перчатки на 10 пальцев человека с приспособлением для быстрого закрепления датчиков на объекте. Номер на креплении соответствует номеру датчика, который будет отображать прибор. Общий вид представлен на рис. 4.

Была проведена апробация работы системы. Сначала датчики были закреплены на левой руке, которая была охлаждена при $-20^{\circ} \mathrm{C}$, в течение $\sim 5 \mathrm{~min}$. Затем подключили датчик правой руки, которая не была охлаждена.

Созданный в АО НПП „Эталон“ прибор для контроля температуры конечностей человека важен для диагностирования и установления степени обморожения. Также данный прибор позволяет оценивать и контролировать действие различных препаратов, примененных к пациенту. В перспективе на основе доработанной и модифицированной версии данного прибора необходимо разработать единую методику для диагностирования хладотравм, которая будет применяться повсеместно.

\section{Список литературы}

[1] Большев К.Н., Иванов В.А., Степанов А.А., Тимофеев А.M. // Вестник МАХ. 2014. № 1. С. 27-30.

[2] Иванов В.А., Большев К.Н., Ефимов В.М., Степанов А.А. // Сельский механизатор. 2014. № 9. С. 36-37.

[3] Nikonenko V.A., Kropachev D.Y., Ivanov V.A. et al. // East European Scientific Journ. 2016. N 6. P. 19-22. 